\title{
Neurophysiologic Study in Children with End Stage Renal Disease on Regular Hemodialysis
}

\author{
Mohammed Fathy Hassan Mohammed ${ }^{1}$ MSc, Moftah Mohammed Rabeea ${ }^{1}$ MD, Hassan Ali Hassan ${ }^{1}$ MD,
} Ann Ali Abd-Elkader ${ }^{1}$ MD, Eman Hassan Mohamed Elzamarany ${ }^{1}$ MD.

* Corresponding Author:

Mohammed Fathy Hassan mofathyhasan88@gmail.com

Received for publication October 16, 2021; Accepted December 19, 2021; Published online December 19, 2021.

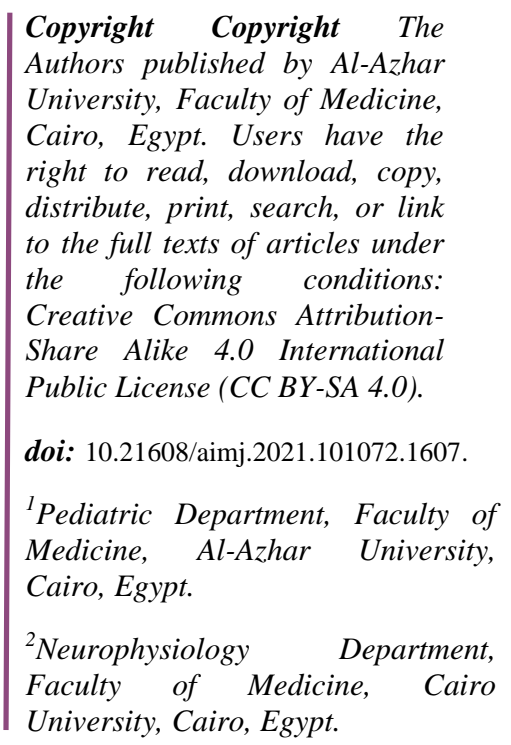
\begin{abstract}
Background: Patients undergoing hemodialysis for chronic kidney disease (CKD) commonly have neurological problems. Both the central and peripheral nerve systems may be affected by these problems. Uremic encephalopathy, cognitive impairment, peripheral neuropathies, and uremic myopathy are all common neurological consequences in CKD.

Aim of the study: to detect neurophysiologic changes using electroencephalography (EEG), nerve conduction velocity (NCV) and electromyography (EMG) in children with CKD on regular hemodialysis and to correlate these changes with duration of dialysis and duration of disease.

Patients and Methods: Thirty patients with CKD who are on regular hemodialysis at pediatric nephrology unit at $\mathrm{Al}$-azher university hospital. With duration of hemodialysis range from (1-13) years. Results: sixteen male and fourteen female mean age (13.50 \pm 2.96$) .16$ cases $(53 \%)$ had polyneuropathy, the majority of which was axonal polyneuropathy, whereas $46.6 \%$ had normal electrophysiological testing. There were no myopathic alterations found. Slowing background and epileptogenic discharges (generalised and focal temporal) were found in $33,3 \%$ of individuals with abnormal EEG.

Results: There was a link between nerve conduction findings and serum potassium and phosphorus levels.

Conclusion: patients on hemodialysis are liable to develop neurological changes as detected by EEG, NCV and EMG due to uremic toxins and electrolytes disturbance. In our results most patients $(53,3 \%)$ showed nerve conduction changes (polyneuropathy) and abnormal EEG changes in $(33,3 \%)$. There was positive correlation between nerve conduction changes and both duration of disease, serum phosphorous and serum potassium.
\end{abstract}

Keywords: electroencephalography; nerve conduction velocity; chronic kidney

disease

Disclosure: The authors have no financial interest to declare in relation to the content of this article. The Article Processing Charge was paid for by the authors.

Authorship: All authors have a substantial contribution to the article. 
$(\mathrm{CKD})^{6}$. Uremic neuropathy is quite frequent in people with CKD, with incidence rates of $60-90$ percent in dialysis patients. Neuropathy that is clinically significant is usually a late consequence that only affects individuals with end-stage renal failure. ${ }^{7}$ In $\mathrm{CKD}$; the development of a myopathy produces proximal muscular weakening and atrophy, primarily in the lower limb muscles. Uremic myopathy is characterised by glomerular filtration rates of less than $25 \mathrm{ml} / \mathrm{min}$ and has been linked to fatigability and decreased exercise capacity. Because electromyography and creatine kinase values are usually normal, the diagnosis is based mostly on clinical evidence. ${ }^{8}-9$

This work was aimed to demonstrate the neurophysiologic changes using EEG, NCV and EMG in children with CKD on regular hemodialysis and to correlate these changes with duration of dialysis and duration of disease.

\section{PATIENTS AND METHODS}

A cross sectional study was done on 30 children with chronic kidney disease on regular hemodialysis. Patients were selected from the Pediatric Nephrology Unit at Al-Azhar University Hospitals according to certain inclusion and exclusion criteria. Patients included in this study their age ranged from (6-18) year and there were on regular hemodialysis for more than 1 year.

They were 16 males and 14 females, mean age $(13.50 \pm 2.96$ year). Patients having primary central or peripheral nervous system disease from congenital or other causes than CKD, patients have systemic disease affecting nervous system and patients receiving medication affecting nervous system were excluded from the study.

\section{Ethical consideration}

All studied participants were had to complete prenatal history, development history, onset and course of ESRD, previous medication, family history of similar condition, detailed family history of genetic disease, duration of dialysis, history of drug intake, history of bone affection and neurological clinical, complete physical examination. Investigations in form of $\mathrm{CBC}$, serum urea, serum creatinine, serum potassium, serum sodium, parathyroid hormone, serum phosphorus, alkaline phosphatase, serum calcium were done. Nerve conduction (NC), electromyography (EMG) and electroencephalography (EEG) were done to participants.

\section{Neurophysiological Studies:}

\section{A) Nerve Conduction Study and Electromyography:}

Neurophysiology investigations as nerve conduction, including sensory and motor assessment, as well as electromyography, were performed on all patients in the current study. In lower limb, the tibial and peroneal nerves on both sides (motor) and (sensory) were evaluated. Upper limb with median and ulnar nerves (motor and sensory) in one limb only away from arterio-venous fistula. The tibialis anterior muscle in lower limb and the biceps muscle in upper limb were also investigated.

\section{B) Electroencephalogram:}

Compumedlcs e series equipment was used to do the EEG in a quiet room. The 21-channel EEGs were recorded under normal settings (rest, hyperventilation, and light stimulation); children were observed while lying down with their eyes closed for the duration of the study. EEG data from 19 scalp electrodes were recorded for 20 minutes using the International 10-20 System and an average reference.

\section{Statistical analysis of the data}

The IBM SPSS software programme version 20.0 was used to examine the data that was supplied into the computer. (IBM Corporation, Armonk, NY). Numbers and percentages were used to represent categorical data. The Chi-square test was used to look into the relationship between the categorical variables. When the expected cell counts were fewer than 5, the Monte Carlo correction test was used instead. The Shapiro-Wilk test was used to check for normality in continuous data. Range (minimum and maximum), mean, standard deviation, and median were used to express distributed data. For regularly distributed quantitative data, the student t-test was employed to compare two groups. For not regularly distributed quantitative variables, the Mann Whitney test was employed to compare two groups. The diagnostic performance of the markers was determined using the Receiver Operating Characteristic Curve (ROC), with an area greater than $50 \%$ indicating acceptable performance and an area more than $100 \%$ indicating the best performance for the test. The significance of the acquired results was assessed at a $5 \%$ level of significance.

\section{RESULTS}

Our results showed clinical data of 30 patients; 16 males and 14 females with mean age of $(13.50 \pm$ 2.96). 25 patients were on regular hemodialysis for less than 5 years. Most common causes of chronic kidney disease were congenital kidney and ureter malformation followed by glomerular diseases and unknown etiology (table 1). Five cases showed abnormalities (slowing background). One case of the six patients who showed epileptic discharge has as well slow background (and this case is one of the five cases who showed slow background). EMG showed no abnormalities. NCV showed normal 14 patients, 14 patients with axonal polyneuropathy and 2 patients with demyelinating polyneuropathy (table 2). Laboratories findings of patients (with exception of S. sodium) are abnormal when compared to the

\section{-}


reference ranges for biochemical parameters (Nelson textbook of Pediatrics $20^{\text {th }}$ edition) showed in (table3). There was positive correlation between nerve conduction velocity findings and duration of disease, moreover there was positive correlation between NCV changes and both potassium and phosphorus other parameters showed no definite correlation with NCV findings (table 4). No significant difference was found between findings in EEG \& NCV showed in (table 5).

ROC curve showed positive correlation between nerve conduction finding and both; duration of disease, serum potassium, and serum phosphorus (16 abnormal versus 14 normal).

\begin{tabular}{ll}
\hline & No. $(\%)$ \\
\hline Sex & \\
Male & $16(53.3 \%)$ \\
Female & $14(46.7 \%)$ \\
Age (years) & \\
Mean \pm SD. & $13.50 \pm 2.96$ \\
Median (Min. - Max.) & $14.50(7.0-18.0)$ \\
Duration of hemodialysis (years) & \\
$\quad<3$ & $14(46.7 \%)$ \\
$\quad 3-5$ & $11(36.7 \%)$ \\
$\quad>5$ & $5(16.7 \%)$ \\
Mean \pm SD. & $3.43 \pm 2.61$ \\
Median (Min. - Max.) & $3.0(1.0-13.0)$ \\
Duration of disease (years) & \\
$\quad 1-<5$ & $15(50 \%)$ \\
$5-10$ & $14(46.7 \%)$ \\
$\quad>10$ & $1(3.3 \%)$ \\
Mean \pm SD. & $4.97 \pm 2.92$ \\
Median (Min. - Max.) & $4.50(1.0-13.0)$ \\
Etiology & $12(40 \%)$ \\
Congenital kidney and urinary tract abnormalities & $7(23.3 \%)$ \\
Chronic glomerulonephritis & $2(6.6 \%)$ \\
Lupus nephritis & $2(6.6 \%)$ \\
Hereditary nephritis (Alport Syndrome) & $7(23.3 \%)$ \\
Unknown & \\
\hline
\end{tabular}

Table 1: Clinical data of studied patients $(n=30)$. Our results showed clinical data of 30 patients; 16 males and 14 females with mean age of $(13.50 \pm 2.96)$. 25 patients were on regular hemodialysis for less than 5 years. Most common cause of chronic kidney disease was congenital kidney and ureter malformation followed by glomerular diseases and unknown etiology.

\begin{tabular}{ll}
\hline & No. $(\%)$ \\
\hline $\begin{array}{l}\text { Electroencephalogram } \\
\text { a- Background }\end{array}$ & \\
\hline $\begin{array}{l}\text { Normal background } \\
\text { Slowing background }\end{array}$ & $25(83.3 \%)$ \\
b- Epileptic Discharge & $5(16.7 \%)$ \\
$\quad$ With normal background & $5(83.3 \%)$ \\
$\quad$ With slowing background & $1(16.7 \%)$ \\
Electromyogram & \\
Normal & $30(100 \%)$ \\
Abnormal & $0(0 \%)$ \\
Nerve conduction velocity & \\
Normal & $14(46.7 \%)$ \\
Abnormal & $16(53.3 \%)$ \\
Demyelinating Polyneuropathy & $2(6.7 \%)$ \\
Axonal Polyneuropathy & $14(46.7 \%)$ \\
Electroencephalogram & \\
\hline Normal & $20(66.7 \% \%$ \\
Abnormal & $10(33.3 \%)$
\end{tabular}

Table 2: Distribution of the Studied cases according to electroencephalography, electromyography and nerve conduction velocity $(n=30)$. Five cases showed abnormalities (slowing background). One case of the six patients who showed epileptic discharge has as well slow background (and this case is one of the five cases who showed slow background). EMG showed no abnormalities. NCV showed normal fourteen patients, fourteen patients with axonal polyneuropathy and two patients with demyelinating polyneuropathy. 


\begin{tabular}{lll}
\hline & Mean \pm SD. & $\begin{array}{l}\text { Median } \\
\text { Max. }\end{array}$ \\
\hline Serum Creatinine $(\mathrm{mg} / \mathrm{dl})$ & $8.12 \pm 1.60$ & $7.90(6.0-12.0)$ \\
Urea $(\mathrm{mg} / \mathrm{dl})$ & $150.77 \pm 185.4$ & $112(74.0-1121.0)$ \\
Hemoglobin $(\mathrm{g} / \mathrm{dl})$ & $9.65 \pm 2.09$ & $9.0(7.0-14.0)$ \\
Serum potassium $(\mathrm{mmol} / \mathrm{L})$ & $6.12 \pm 0.30$ & $6.05(5.70-6.80)$ \\
Serum phosphorus $(\mathrm{mg} / \mathrm{dL})$ & $6.98 \pm 0.77$ & $6.95(5.70-8.60)$ \\
Calcium $(\mathrm{mg} / \mathrm{dl})$ & $8.78 \pm 0.98$ & $8.70(7.20-12.0)$ \\
Sodium $(\mathrm{mmol} / \mathrm{L})$ & $136.4 \pm 3.21$ & $137.0(131.0-142.0)$ \\
Alkaline phosphatase $(\mathrm{U} / \mathrm{L})$ & $688.8 \pm 178.8$ & $706.5(245.0-964.0)$ \\
Parathyroid hormone $(\mathrm{ng} / \mathrm{ml})$ & $374.5 \pm 213.2$ & $325.5(86.0-947.0)$ \\
\hline
\end{tabular}

Table 3: Descriptive analysis of the Studied cases according to laboratory investigations $(n=30$; SD: Standard deviation). Laboratories findings of patients (with exception of S. sodium) are abnormal when compared to the reference ranges for biochemical parameters (Nelson textbook of pediatrics 20th edition).

\begin{tabular}{|c|c|c|c|c|c|c|c|c|}
\hline & \multicolumn{2}{|l|}{$\mathrm{NCV}$} & \multirow{2}{*}{$\begin{array}{l}\text { Test of } \\
\text { Sig. }\end{array}$} & \multirow[t]{2}{*}{$\mathrm{p}$} & \multicolumn{2}{|l|}{ EEG } & \multirow{2}{*}{$\begin{array}{l}\text { Test of } \\
\text { Sig. }\end{array}$} & \multirow[t]{2}{*}{$\mathrm{p}$} \\
\hline & $\begin{array}{l}\text { Normal } \\
(n=14)\end{array}$ & $\begin{array}{l}\text { Abnormal } \\
(\mathrm{n}=16)\end{array}$ & & & $\begin{array}{l}\text { Normal } \\
(\mathrm{n}=20)\end{array}$ & $\begin{array}{l}\text { Abnormal } \\
(\mathrm{n}=10)\end{array}$ & & \\
\hline \multicolumn{9}{|c|}{$\begin{array}{l}\text { Duration of hemodialysis } \\
\text { (years) }\end{array}$} \\
\hline$<3$ & $8(57.1 \%)$ & $6(42.9 \%)$ & \multirow{3}{*}{$\begin{array}{l}\chi 2= \\
1.946\end{array}$} & \multirow{3}{*}{$\begin{array}{l}\mathrm{MCp}= \\
0.438\end{array}$} & $10(71.4 \%)$ & $4(28.6 \%)$ & \multirow{3}{*}{$\begin{array}{l}\chi 2= \\
0.503\end{array}$} & \multirow{3}{*}{$\begin{array}{l}\mathrm{MCp}= \\
1.000\end{array}$} \\
\hline $3-5$ & $5(45.5 \%)$ & $6(54.5 \%)$ & & & $7(63.6 \%)$ & $4(36.4 \%)$ & & \\
\hline$>5$ & $1(20.0 \%)$ & $4(80.0 \%)$ & & & $3(60.0 \%)$ & $2(40.0 \%)$ & & \\
\hline Mean \pm SD & $2.86 \pm 1.92$ & $3.94 \pm 3.07$ & \multirow{2}{*}{$\begin{array}{l}\mathrm{U}= \\
89.0\end{array}$} & \multirow[t]{2}{*}{0.355} & $3.30 \pm 2.90$ & $3.70 \pm 2.0$ & \multirow{3}{*}{$\begin{array}{l}\mathrm{U}= \\
78.50\end{array}$} & \multirow[t]{2}{*}{0.350} \\
\hline Median (Min. - Max.) & $2.0(1.0-8.0)$ & $3.50(1.0-13.0)$ & & & $2.50(1-13)$ & $4.50(1-6)$ & & \\
\hline \multicolumn{8}{|c|}{ Duration of disease (years) } & \\
\hline Mean \pm SD & $3.07 \pm 1.86$ & $6.63 \pm 2.68$ & \multirow{3}{*}{$\begin{array}{l}\mathrm{U}= \\
26.50 *\end{array}$} & \multirow{2}{*}{$<0.001 *$} & $5.0 \pm 3.20$ & $4.90 \pm 2.42$ & \multirow{2}{*}{$\begin{array}{l}\mathrm{U}= \\
95.0\end{array}$} & \multirow[t]{2}{*}{0.846} \\
\hline Median (Min. - Max.) & $2.50(1.0-8.0)$ & $6.0(2.0-13.0)$ & & & $4.0(1.0-13.0)$ & $5.0(1.0-9.0)$ & & \\
\hline \multicolumn{8}{|l|}{ Serum Creatinine $(\mathrm{mg} / \mathrm{dl})$} & \\
\hline Mean \pm SD & $7.84 \pm 1.51$ & $8.36 \pm 1.68$ & \multirow{3}{*}{$\begin{array}{l}\mathrm{t}= \\
0.885\end{array}$} & \multirow{2}{*}{0.384} & $8.29 \pm 1.72$ & $7.78 \pm 1.33$ & \multirow{3}{*}{$\begin{array}{l}\mathrm{t}= \\
0.819\end{array}$} & \multirow[t]{3}{*}{0.419} \\
\hline Median (Min. - Max.) & $7.40(6.0-12.0)$ & $8.0(6.0-12.0)$ & & & $8.0(6.0-12.0)$ & $7.0(6.80-10.0)$ & & \\
\hline \multicolumn{6}{|l|}{ Urea (mg/dl) } & & & \\
\hline Mean \pm SD & $189.9 \pm 269.5$ & $116.6 \pm 28.66$ & $\mathrm{U}=$ & 0.608 & $170.3 \pm 225.82$ & $111.7 \pm 23.69$ & $\mathrm{U}=$ & 0.397 \\
\hline Median (Min. - Max.) & $118(74-1121)$ & $111(83-185)$ & 99.0 & & $117.5(74-1121)$ & $110.0(83-151)$ & 80.50 & \\
\hline $\mathrm{Hb}(\mathrm{g} / \mathrm{dl})$ & & & & & & & & \\
\hline Mean \pm SD & $9.19 \pm 1.74$ & $10.06 \pm 2.32$ & $\mathrm{t}=$ & 0.258 & $9.30 \pm 1.72$ & $10.36 \pm 2.63$ & & 0.269 \\
\hline Median (Min. - Max.) & $9.0(7.0-14.0)$ & $9.50(7.0-14.0)$ & 1.155 & & $9.0(7.0-14.0)$ & $9.50(7.60-14.0)$ & 1.155 & \\
\hline Serum potassium (mmo & & & & & & & & \\
\hline Mean \pm SD & $5.91 \pm 0.12$ & $6.29 \pm 0.31$ & $\mathrm{t}=$ & $<0.001 *$ & $6.05 \pm 0.25$ & $6.26 \pm 0.36$ & & 0.067 \\
\hline Median (Min. - Max.) & $5.90(5.70-6.10)$ & $6.40(5.70-6.80)$ & $4.550^{*}$ & & $6.0(5.70-6.60)$ & $6.35(5.70-6.80)$ & 1.907 & \\
\hline Serum phosphorus (mg/ & & & & & & & & \\
\hline Mean \pm SD & $6.59 \pm 0.54$ & $7.32 \pm 0.80$ & $\mathrm{t}=$ & $0.008^{*}$ & $6.95 \pm 0.71$ & $7.04 \pm 0.92$ & & 0.769 \\
\hline Median (Min. - Max.) & $6.55(6.0-7.50)$ & $7.25(5.70-8.60)$ & $2.877^{*}$ & & $6.95(6.0-8.40)$ & $6.95(5.70-8.60)$ & 0.297 & \\
\hline Serum calcium (mg/dl) & & & & & & & & \\
\hline Mean \pm SD & $8.65 \pm 0.49$ & $8.89 \pm 1.27$ & $\mathrm{t}=$ & 0.515 & $8.55 \pm 0.77$ & $9.23 \pm 1.21$ & & 0.071 \\
\hline Median (Min. - Max.) & $8.60(8.0-9.40)$ & $8.80(7.20-12.0)$ & 0.659 & & $8.45(7.20-10.70)$ & $9.0(8-12)$ & 1.877 & \\
\hline Serum $\mathrm{Na}+(\mathrm{mmol} / \mathrm{L})$ & & & & & & & & \\
\hline Mean \pm SD & $136.29 \pm 2.84$ & $136.50 \pm 3.60$ & $\mathrm{t}=$ & 0.859 & $136.2 \pm 3.18$ & $136.9 \pm 3.38$ & & 0.556 \\
\hline Median (Min. - Max.) & $137(132-141)$ & $136.5(131-142)$ & 0.179 & & $136.5(131-141)$ & $137.5(131-142)$ & 0.596 & \\
\hline Alkaline phosphatase ( & & & & & & & & \\
\hline Mean \pm SD. & $727.9 \pm 160.0$ & $654.6 \pm 192.2$ & $\mathrm{t}=$ & 0.271 & $701.6 \pm 210.5$ & $663.2 \pm 91.62$ & & 0.493 \\
\hline Median (Min. - Max.) & $749(432-964)$ & $633(245-956)$ & 1.124 & & $740.5(245-964)$ & $633.0(527-803)$ & 0.695 & \\
\hline PTH (ng/dl) & & & & & & & & \\
\hline Mean \pm SD & $350.8 \pm 221.8$ & $395.3 \pm 210.4$ & $\mathrm{U}=$ & 0.525 & $342.2 \pm 192.0$ & $439.1 \pm 248.3$ & $\mathrm{U}=$ & 0.267 \\
\hline Median (Min. - Max.) & $304(86-947)$ & $335(138-834)$ & 96.50 & & $315.5(86-834)$ & $439.0(161-947)$ & 74.50 & \\
\hline
\end{tabular}

Table 4: Relation between NCV and EEG with different parameters. There was positive correlation between nerve conduction velocity findings and duration of disease, moreover there was positive correlation between NCV changes and both potassium and phosphorus other parameters showed no definite correlation with NCV findings. (SD: Standard deviation; t: Student t-test; U: Mann Whitney test; $\chi 2$ : Chi square test $\quad$; MC: Monte Carlo; $p: p$ value for comparing between the studied groups; *: Statistically significant at $p \leq 0.05$ ).

\begin{tabular}{|c|c|c|c|c|}
\hline \multirow[t]{2}{*}{ Electroencephalogram } & \multicolumn{2}{|c|}{ Nerve conduction velocity } & \multirow[t]{2}{*}{$\chi^{2}$} & \multirow[t]{2}{*}{$\mathbf{p}$} \\
\hline & $\begin{array}{l}\text { Normal } \\
(\mathrm{n}=14)\end{array}$ & $\begin{array}{l}\text { Abnormal } \\
(\mathrm{n}=16)\end{array}$ & & \\
\hline Normal background & $11(78.6 \%)$ & $9(56.3 \%)$ & \multirow[t]{2}{*}{1.674} & \multirow[t]{2}{*}{0.260} \\
\hline Abnormal background & $3(21.4 \%)$ & $7(43.8 \%)$ & & \\
\hline
\end{tabular}

Table 5: Relation between nerve conduction velocity and electroencephalogram. $\left(\chi^{2}\right.$ : Chi square test; $\mathrm{p}: \mathrm{p}$ value for comparing between the studied groups. 


\begin{tabular}{|c|c|c|c|c|c|c|c|c|}
\hline & AUC & $\mathbf{p}$ & 95\% C.I & $\begin{array}{l}\text { 节 } \\
\stackrel{\Xi}{\Xi}\end{array}$ & : & 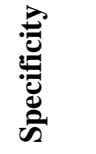 & a & z \\
\hline $\begin{array}{l}\text { Duration of disease } \\
\text { (years) }\end{array}$ & 0.882 & $<0.001^{*}$ & $0.753-1.000$ & $>4$ & 81.25 & 85.71 & 86.7 & 80.0 \\
\hline Serum potassium (mg/dl) & 0.862 & $0.001 *$ & $0.714-1.000$ & $>6$ & 81.25 & 85.71 & 86.7 & 80.0 \\
\hline Serum phosphorus (mg/dl) & 0.761 & $0.015^{*}$ & $0.583-0.939$ & $>7.1$ & 62.50 & 85.71 & 83.3 & 66.7 \\
\hline
\end{tabular}

Table 6: Validity (AUC, sensitivity, specificity) for D.O.D (years), serum potassium and Serum phosphorus to discriminate Abnormal NCV patients $(n=16$ vs. 14). No significant difference was found between findings in EEG \& NCV. AUC: (Area Under a Curve; p value: Probability value; CI: Confidence Intervals; NPV: Negative predictive value; PPV: Positive predictive value; *: Statistically significant at $\mathrm{p} \leq 0.05$; \#Cut off was choose according to Youden index).
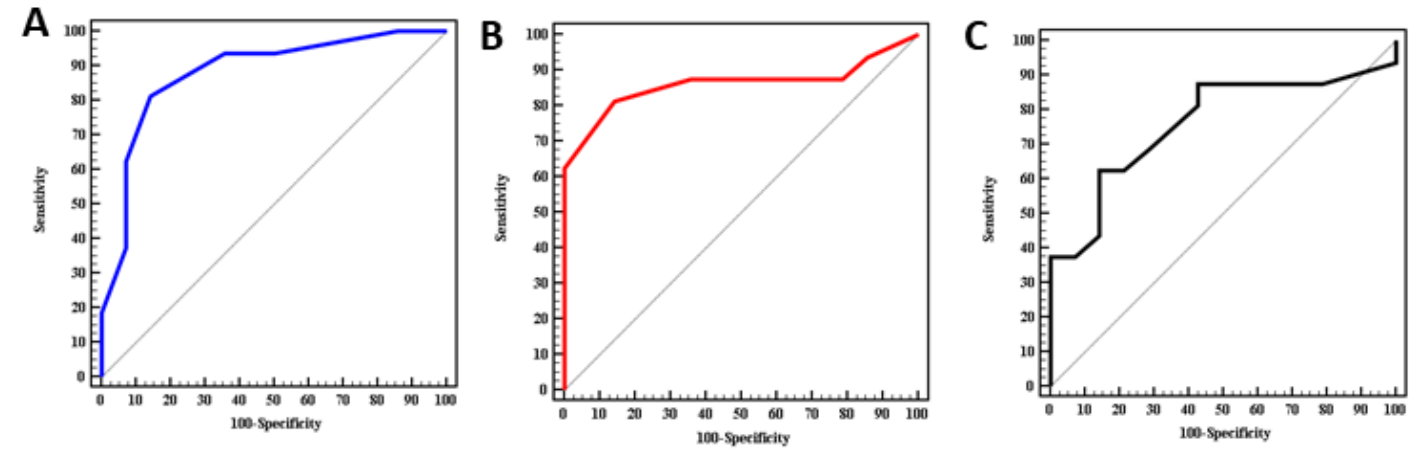

Fig 1: A: ROC curve for duration of disease (years) to discriminate Abnormal NCV patients ( $\mathrm{n}=16$ vs. 14). B: ROC curve for serum $\mathrm{k}$ to discriminate Abnormal NCV patients ( $\mathrm{n}=16$ vs. 14 ). C: ROC curve for serum $\mathrm{P}$ to discriminate Abnormal NCV patients ( $\mathrm{n}=16$ vs. 14). ROC curve showed positive correlation between nerve conduction finding and both; duration of disease, serum potassium, and serum phosphorus (16 abnormal versus 14 normal).

\section{DISCUSSION}

Chronic kidney disease (CKD) is a major public health issue that affects people all over the world. It's well acknowledged as one of the most prevalent conditions linked to an elevated risk of various organ malfunction ${ }^{10}$.

Almost all patients with CKD have neurological problems, which may impact all levels of the nervous system, from the central nervous system to the peripheral nerve system ${ }^{7}$.Our study was done to find out neurophysiological changes in pediatric patients with chronic renal failure and on regular hemodialysis and to evaluate the effects of chronic renal failure on central nervous system and peripheral nervous system. Central and peripheral nervous system function were evaluated with the EEG, EMG and measurements of nerve conduction velocity (NCV), respectively.

The present study included 30 patients with chronic renal failure and on regular hemodialysis with mean ages of $13.50 \pm 2.96$ years. They were 16 were females and the remaining 14 children were males. This agree with ${ }^{11}$ who found in their study which included 50 children ( 27 were female and 23 were males) age of $12.8 \pm 3.44$ year.
The most common causes of CKD in our study were congenital kidney and ureter abnormalities in form of obstructive uropathy (PUV and PUJO) and cystic kidney disease detected in 12 patients (40\%) followed by chronic glomerulonephritis $23 \%$ and unknown etiology $23 \%$. This in concordance with ${ }^{12}$ who found that most common cause of chronic renal disease in pediatric patients was obstructive uropathy $21 \%$ of cases followed by unknown etiology in $20 \%$ of causes.

According to duration of hemodialysis, all cases in the study were distributed as follow: 14 cases $(46.7 \%)$ on regular hemodialysis for less than 3 years, 11 cases $(36.7 \%)$ for $3-5$ years and the remaining 5 cases $(16.7 \%)$ for more than 5 years.

The distribution of children with abnormal NCV (16 patients) and EEG changes (10 patients) according to duration of hemodialysis showed that

a- From the 14 patients on regular hemodialysis for less than 3 years, 6 of them $(42.9 \%)$ have polyneuropathy while 4 cases (28.6\%) have EEG changes.

b- From the 11 patients on regular hemodialysis for 3-5 years, 6 of them (54.5\%) have polyneuropathy while 4 patients of them $(36.4 \%)$ showed EEG changes. 
c- From the remaining 5 patients on regular hemodialysis for more than 5 year, 4 of them (80\%) showed polyneuropathy while only 2 of them $(40 \%)$ showed EEG abnormalities.

We found that $53.3 \%$ of our patients had polyneuropathy (16 out of 30 ). Axonal neuropathy was the most common form detected in 14 patients (87.5\%) followed by 2 patients with demyelinating polyneuropathy $(12.5 \%)$. In our study we found 10 patients $(33.3 \%)$ with EEG abnormalities. 4 patients with epileptic discharge (1 patient generalized epileptic discharge, 3 patients with focal sharp wave in temporal area) and 1 patient (3.3\%) with slowing and epileptic discharge (generalized)

This may be attributed to length-dependent axonal degradation and subsequent localized loss of myelin sheaths in uremic neuropathy, which is characterised by distal symmetric sensorimotor polyneuropathy that generally affects the lower limbs ${ }^{13}$. This is a demyelinating disease in which axonal degeneration and loss occur.

Also increased oxidative stress and production of free radicals can play important role in pathogenesis of polyneuropathy

Uremic neuropathy is caused by the buildup of uremic toxins (the "middle toxins," which include guanidine molecules, parathyroid hormone, and myoinositol) ${ }^{14}$.

We found in our study a significant correlation in patients with polyneuropathy between nerve conduction damage and both serum potassium and phosphorous.

This can be explained by decrease in excretion of both potassium and phosphorus in patient on regular hemodialysis leading to hyperkalemia and hyperphosphatemia ${ }^{7}$. Nerve excitability studies showed a connection between axonal membrane dysfunction and blood potassium levels throughout the course of a dialysis session, suggesting that hyperkalemia plays a role in the development of neuropathy in CKD patients.

As regard EMG for tibialis anterior in lower limb muscle and biceps muscle in upper limb; we did not find any EMG changes. This can be explained by relatively short duration of dialysis in the majority of cases which was not enough to cause changes in the muscle. Our data are supported by those of ${ }^{8}$ who reported that easy fatigability and reduced exercise capacity can occur in patients on regular hemodialysis but electromyography and creatine kinase levels are generally normal.

Although the nerve conduction abnormalities and EEG changes increase with prolonged duration of hemodialysis, the correlation was not significant. This can be explained by small sample size and the relatively short duration of hemodialysis.
The causes of central nervous system dysfunction in CKD are complex and cannot be ascribed simply to an increase in blood urea levels. Guanidino chemicals are another potential harmful mechanism (GCs). Four GCs (creatinine, guanidine, guanidinosuccinic acid, and methyl guanidinosuccinic acid) were shown to be significantly elevated in CKD patients' blood, brain, and CSF fluid ${ }^{15}$. Furthermore, uremic toxins such as nitric oxide synthase, GC modulation, decreased brain energy demand, specific free amino acid changes, blood-brain barrier disruption, and vascular disease have been associated to CKD neurologic sequelae $e^{16}$.

\section{CONCLUSION}

Patients on hemodialysis are liable to develop neurological changes as detected by EEG, NCV and EMG due to uremic toxins and electrolytes disturbance. Nerve conduction velocity showed abnormal findings in most of our patients. EEG abnormal findings were present in one third of our patients. There was positive correlation between duration of disease and nerve affection. There was positive correlation between both serum potassium and phosphorus and nerve conduction findings on other hand.

\section{REFERENCES}

1. Levy J, Morgan J, Brown E, et al. Hemodialysis, Dialysis adequacy. Oxford Handbook of Dialysis, Oxford Med online. 2011; 2:71-195.

2. Karunaratne K, Taube D, Khalil N, et al. Neurological complications of renal dialysis and transplantation. Pract Neurol. 2018;18(2):11525 .

3. Kerecuk L, Schreuder MF and Woolf AS. Human renal tract malformations: perspectives for Nephrologists. Nat Clin Pract Nephrol. 2008; 4:312-25.

4. Levin A, Stevens PE, Bilous RW, et al. kidney disease: Improving Global Outcomes (KDIGO) CKD Work Group. KDIGO 2012 clinical practice guideline for the evaluation and management of chronic kidney disease. Kidney international supplements. 2013; 3(1):1-50.

5. Gadewar P, Sourya A, Praveen K, et al. Dynamics of Electroencephalogram (EEG) in Different Stages of Chronic Kidney Disease. Journal of Clinical and Diagnostic Research. 2015; 9(3): 25-7.

6. Harrison T, Wiener C, Brown C, et al. Harrison's Principles of Internal Medicine. 18th ed. New York: McGraw-Hill Medical; 2012.

7. Krishnan AV and Kiernan MC. Neurological complicationsof chronic kidney disease. Nat Rev Neurol. 2009; 5:542-5.

8. Campistol, JM. Uremic myopathy. Kidney Int. 2002; 62, 1901-13.

\section{.}

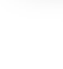


9. Kaltsatou A, Sakkas GK, Poulianiti KP , et al. Uremic myopathy: is oxidative stress implicated in muscle dysfunction in uremia? Front Physiol 2015; 6: 102.

10. K/DOQI clinical practice guidelines for chronic kidney disease: evaluation, classification, and stratification. Kidney Disease Outcome Quality Initiative. Am J Kidney Dis. 2002; 39:1-246.

11. Abd El Naby, Sameh A., et al. Neurophysiological and Neuroradiological Changes in children with chronic kidney disease. Frontiers in Pediatrics. 2020; 8.

12. Safouh H., Fadel F., Essam R. Causes of chronic kidney disease in Egyptian children. Saudi J Kidney Dis Transpl. 2015; 26:806-9.

13. Ghazan-Shahi S, Koh TJ, Chan CT. Impact of nocturnal hemodialysis on peripheral uremic neuropathy. BMC Nephrol. 2015; 16:134.

14. Kandil MR, Darwish ES, Khedr EM, et al. A community-based epidemiological study of peripheral neuropathies in Assiut, Egypt. Neurol Res. 2012; 34(10):960-6.

15. De Deyn PP, D’Hooge R, Van Bogaert PP, et al. Endogenous guanidine compounds as uremic neurotoxins. Kidney Int. 2001;59: 77-83.

16. Liu M, Liang Y, Chigurupati S, et al. Acute kidney injury leads to inflammation and functional changes in the brain. $J A m$ Soc Nephrol. 2008; 19:1360-70. 